\title{
MUDANÇAS DO CLIMA OU NA CONDIÇÃO DA COBERTURA E USO DO SOLO PRÓXIMA ÀS ESTAÇÕES METEOROLÓGICAS (?)
}

\author{
Diego Tarley Ferreira Nascimento ${ }^{\text {(a) }}$ \\ (a) Departamento de Geografia, Universidade Estadual de Goiás - Campus Iporá, diego.tarley@ gmail.com
}

\section{Eixo: 3. CLIMATOLOGIA EM DIFERENTES NÍVEIS ESCALARES: MUDANÇAS E VARIABILIDADES}

\begin{abstract}
Resumo
Considerando-se o crescimento das cidades, muitas estações anteriormente localizadas em áreas rurais se encontram atualmente incorporadas às áreas urbanas, refletindo algumas tendências de aumento ou declínio dos elementos climáticos. O presente trabalho tem por objetivo averiguar a condição da cobertura e uso do solo próxima às estações meteorológicas, tendo como recorte amostral a rede de estações meteorológicas (convencional e automática) do Instituto Nacional de Meteorologia (INMET). Para tanto, as estações meteorológica foram interceptadas por imagem de luzes noturnas estabilizadas na superfície, classificadas em áreas urbanas, semiurbanas e não urbanas. Do total de 710 estações meteorológicas do INMET, 381 estão localizados em áreas urbanas (53,7\%), 254 em áreas semiurbanas $(35,8 \%)$ e 75 em áreas não urbanas $(10,6 \%)$, indicando que os dados meteorológicos registados atualmente sofram a influência de zonas urbanizadas. Contudo, essa proporção varia entre as regiões brasileiras e, principalmente, entre as estações do tipo convencional e automática.
\end{abstract}

Palavras chave: mudanças, clima, estações, meteorológicas, cobertura.

\section{Introdução}

O conhecimento do estado e da variabilidade dos elementos climáticos é uma necessidade do homem desde os tempos remotos, uma vez que o planejamento das atividades de caça, cultivo e deslocamento dependiam (e dependem) diretamente da condição do tempo e do clima. Nos primórdios, referências aos elementos climáticos eram explicadas e justificadas pelo misticismo e, posteriormente, estimadas com base em observações indiretas feitas em descrições e relatos de naturalistas e viajantes, principalmente das grandes explorações geográficas promovidas pelos europeus a partir do século XV.

A invenção e o desenvolvimento de instrumentos meteorológicos a partir do século XV subsidiou o conhecimento dos reais valores dos elementos climáticos de dada localidade.

No Brasil, a observação meteorológica passou a ser realizada de forma sistemática apenas em 1910 pelo Instituto Nacional de Meteorologia (INMET). Até o final da década de 60, havia cerca de 209 estações meteorológicas instaladas no país e, atualmente, esse órgão dispõe de cerca de 237 estações convencionais e 473 estações automáticas - totalizando 710 estações, vistas pela Figura 1. Contudo, algumas estações convencionais do INMET encontram-se em processo de desativação para implantação de estações 


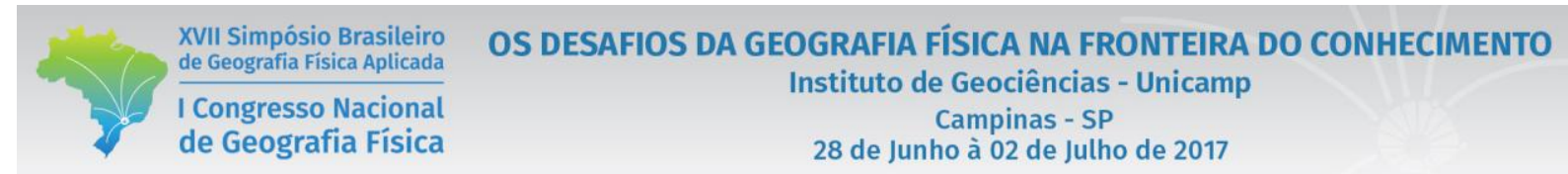

automáticas, o que, em alguns casos, não ocorre na mesma localidade. Ainda, apesar de maior quantidade, vale destacar que a instalação da maioria das estações automáticas se deu nas últimas duas décadas.

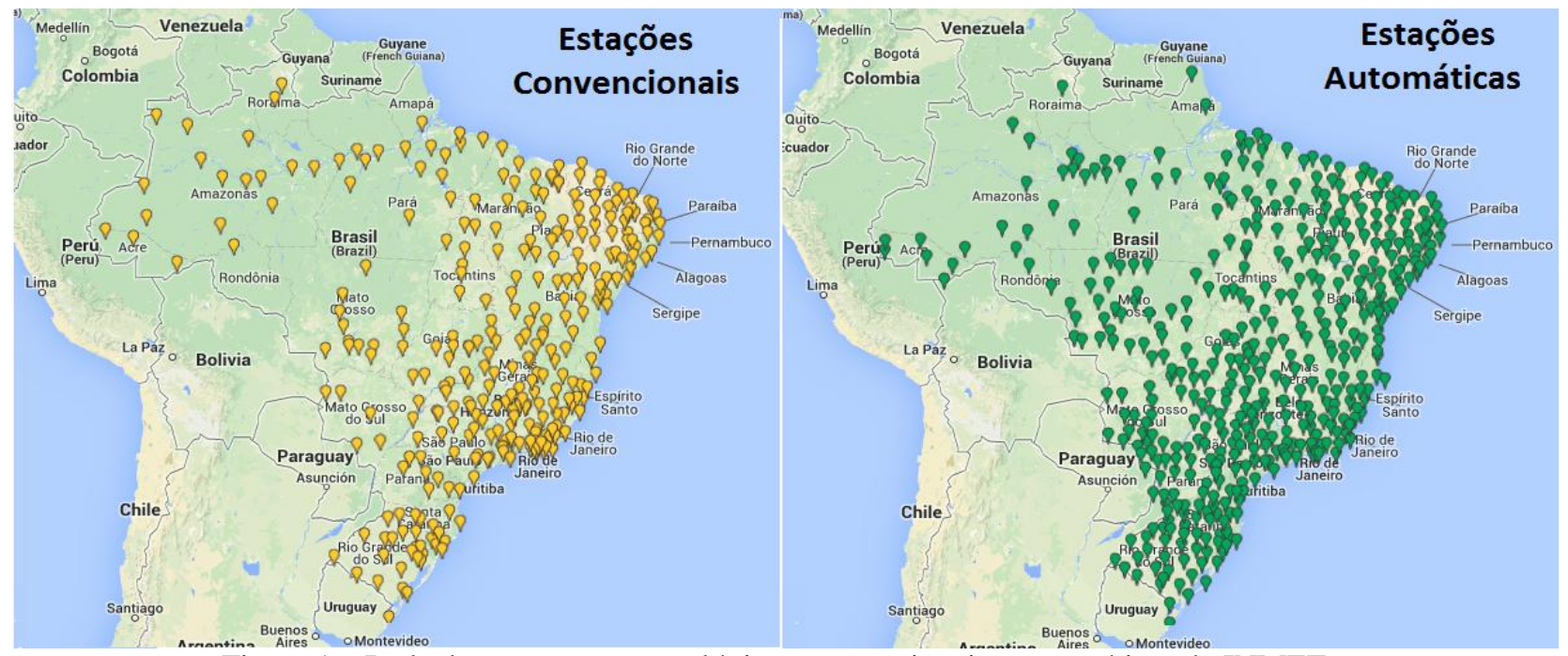

Figura 1 - Rede de estações meteorológicas convencionais e automáticas do INMET.

Fonte: INMET (com adaptações).

Contudo, mesmo se tratando de medições diretas, os dados registrados por estações meteorológicas podem apresentar uma série de problemas, tais como: 1) a qualidade dos registos que dependem do tipo de material utilizado nas estações; 2) a distribuição rarefeita e desigual da rede de estações; 3) os erros nas leituras ou a interrupção na coleta/registro; 4) os defeitos que os instrumentos podem apresentar; 5) as mudanças de equipamentos ou mesmo do lugar onde a estação está localizada e; 6) as mudanças na cobertura e uso do solo próximo às estações (DUBREUIL, 2005; SU, HONG, LETTENMAIER, 2007; YANG ET AL, 2013).

Conforme lembrado por Rozante et al. (2010), os dados registrados por estações são considerados como verdades brutas, sem qualquer análise mais acurada ou desconfiança com relação à qualidade ou validade dos dados registrados.

Em tempo de ampla discussão a respeito das mudanças climáticas, pouca atenção tem sido dada às condições da cobertura e uso do solo próximas às estações meteorológicas. Considerando-se o crescimento das cidades, muitas estações anteriormente localizadas em áreas rurais se encontram atualmente incorporadas às áreas urbanas, o que pode ter refletido tendência de aumentou ou declínio dos elementos climáticos.

Assim, o presente trabalho tem por objetivo averiguar a condição da cobertura e uso do solo próxima às estações meteorológicas do Brasil, essencialmente no que diz respeito à situação das mesmas em áreas 


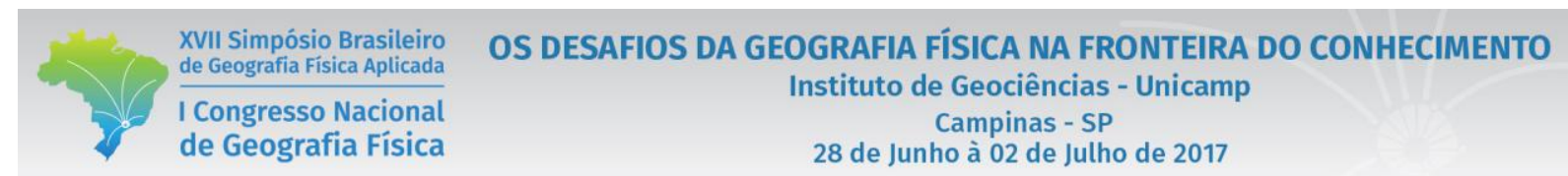

urbanas, semiurbanas ou não urbanas, a fim de proporcionar subsídios à discussão das mudanças climáticas por meio de uma reflexão da influência da urbanização no entorno das estações meteorológicas.

\section{Procedimentos Metodológicos}

Para desenvolvimento do trabalho, as estações meteorológicas convencionais e automáticas do Instituto Nacional de Meteorologia (INMET) foram interceptadas em ambiente de Sistemas de Informações Geográficas (ArcGIS 10.1) por imagem de luzes noturnas estabilizadas na superfície, registrada pelo Defense Meteorological Satellite Program (DMPS). Foi utilizada a imagem referente a 2012, com uma resolução espacial de $1 \mathrm{~km}$, sendo os valores digitais dos pixels classificados em urbano, semiurbano ou não urbano por quebra natural a partir do histograma.

A definição da condição da cobertura do solo no entorno das estações e a sua classificação em estação urbanizada, semiurbanizadas ou não urbanizada se deu pela interceptação do arquivo vetor (pontos) representando as estações meteorológicas com o arquivo matricial da imagem de luzes noturnas, conforme visto pela Figura 2, que exemplifica a estações de Uberlândia (a sudeste), Ituiutaba (a sudoeste) e Capinópolis (a oeste) situadas em área urbana, semiurbana e não urbana, respectivamente.

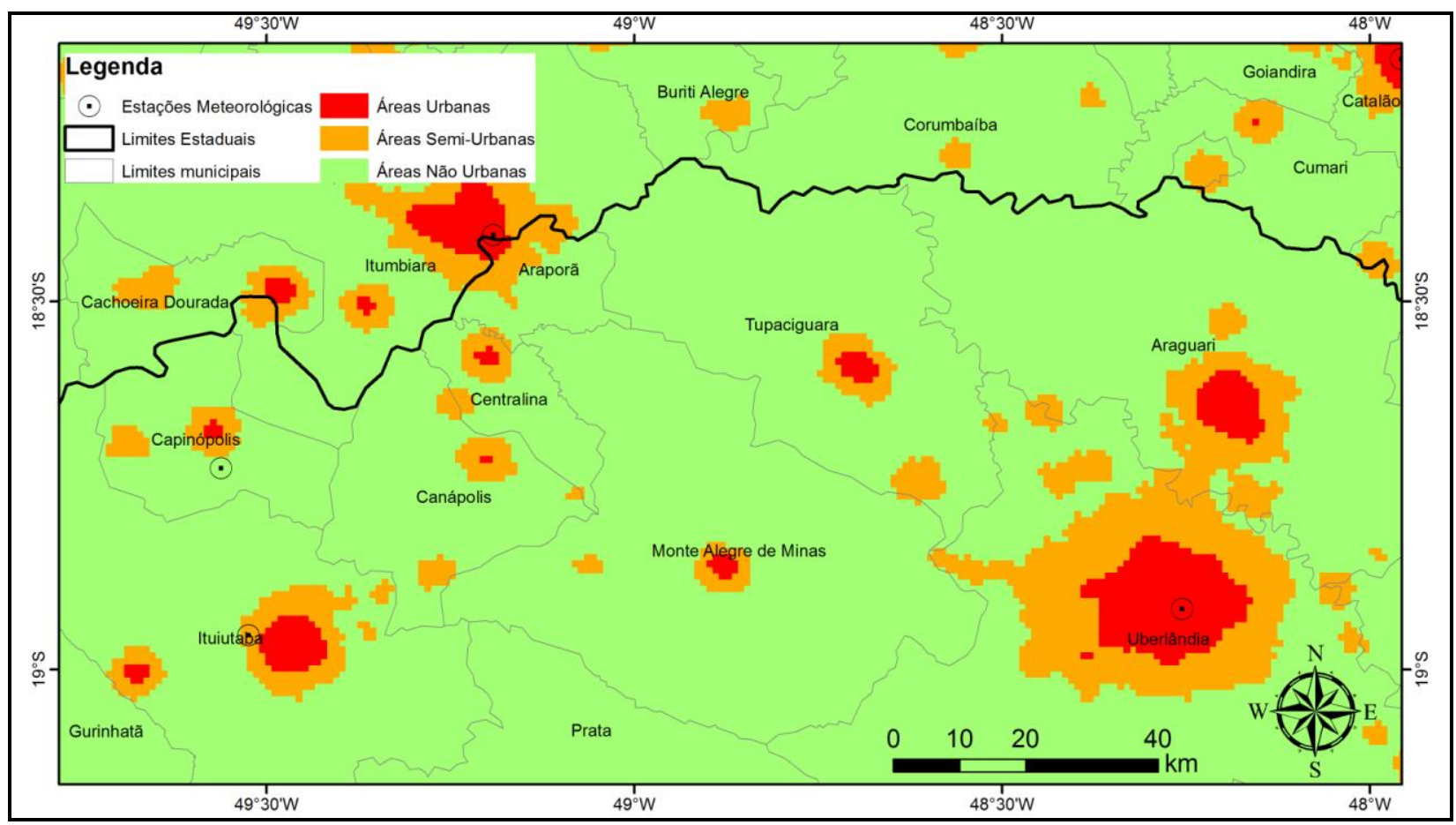

Figura 2 - Recorte amostral representando a situação de algumas estações meteorológicas do INMET. Elaboração: próprio autor. 


\section{Resultados e Discussões}

Do total de 710 estações meteorológicas da rede do INMET existentes no território brasileiro, 381 estão localizadas em áreas urbanas (53,7\%), 254 em áreas semiurbanas (35,8\%) e 75 em áreas não urbanas $(10,6 \%)$ - Figura 3. Ou seja, quase metade das estações está situada em áreas urbanizadas, o que sugere que os dados por elas registrados estejam sofrendo a influência da urbanização.

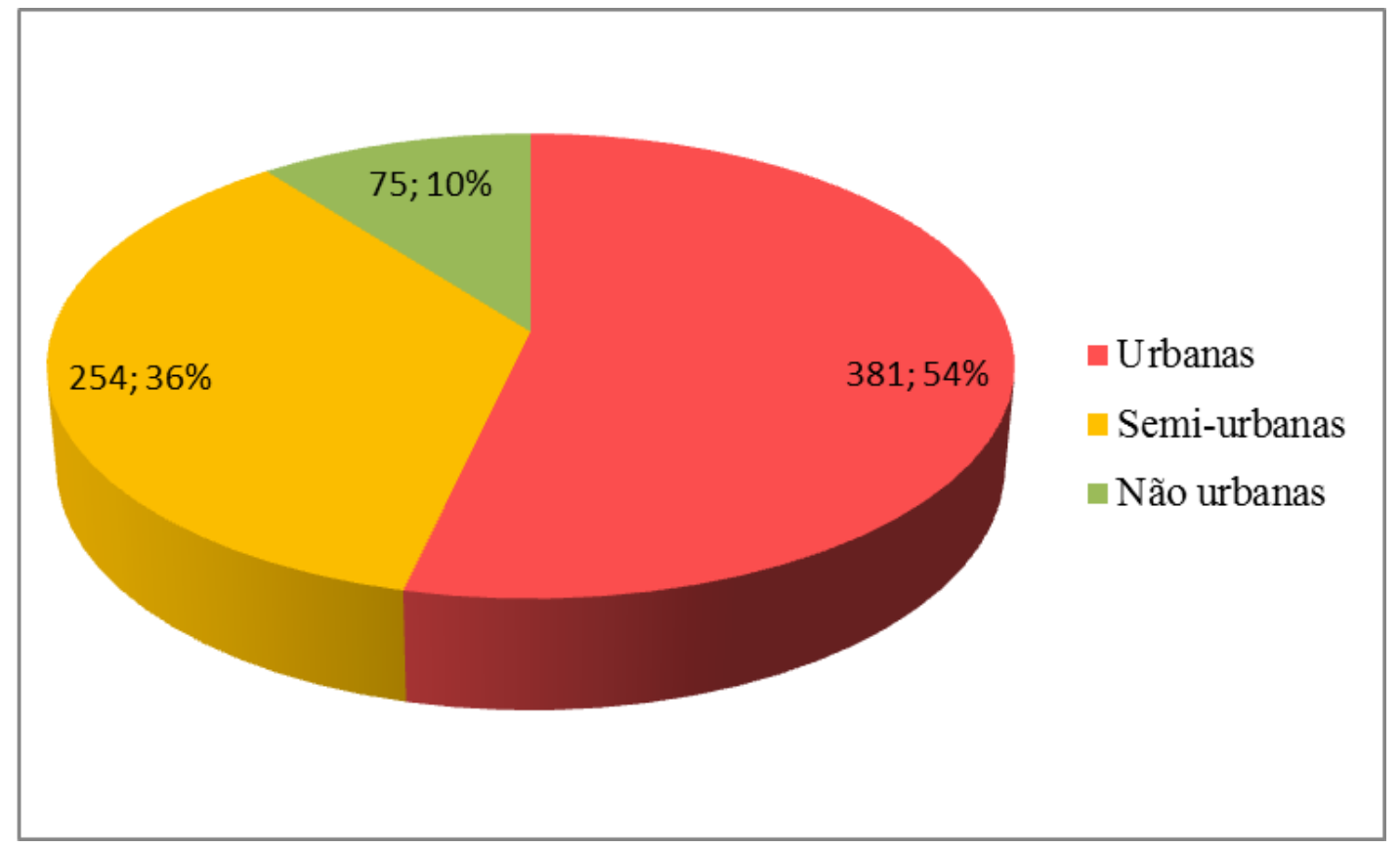

Figura 3 - Gráfico da classificação da situação das estações meteorológicas do INMET Elaboração: próprio autor, calculado em SIG.

Conforme visto pela Figura 4 e por meio do Quadro 1, ambos na sequência, do montante de 381 estações meteorológicas situadas em áreas urbanas, $31 \%$ se encontram na região Nordeste e outros $25 \%$ na região Sudeste. As unidades da federação com maior proporção de estações situadas em áreas urbanas são Minas Gerais $(12,9 \%)$ e Bahia $(12,2 \%)$.

O padrão verificado com relação às estações situadas em área urbanas se repete com aquelas em áreas semiurbanas, com maior concentração dessa condição nas regiões Nordeste $(34,3 \%)$ e Sudeste $(18,1 \%)$, tendo maior destaque para os estados de Minas Gerais (11\%) e Bahia (9,8\%).

Já no que se refere às estações situadas em áreas não urbanas, o predomínio se dá nas regiões Sudeste (24\%), Norte $(21,3 \%)$ e Centro-Oeste (20\%), traduzindo, em primeiro lugar, que a região Sudeste concentra maior proporção das estações meteorológicas, independente de estarem situadas em áreas urbanas ou não, e, num segundo momento, que as regiões Norte e Centro-Oeste apresentam maior 


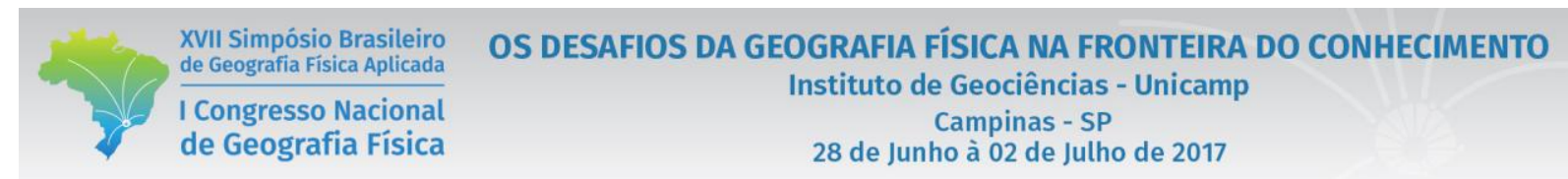

proporção de estações situadas em áreas não urbanizadas. Em se tratando das unidades federativas, maior proporção de estações em áreas não urbanizadas ocorre em Minas Gerais (18,7\%), Mato Grosso (16\%), Pará (8\%) e Maranhão (6,7\%).

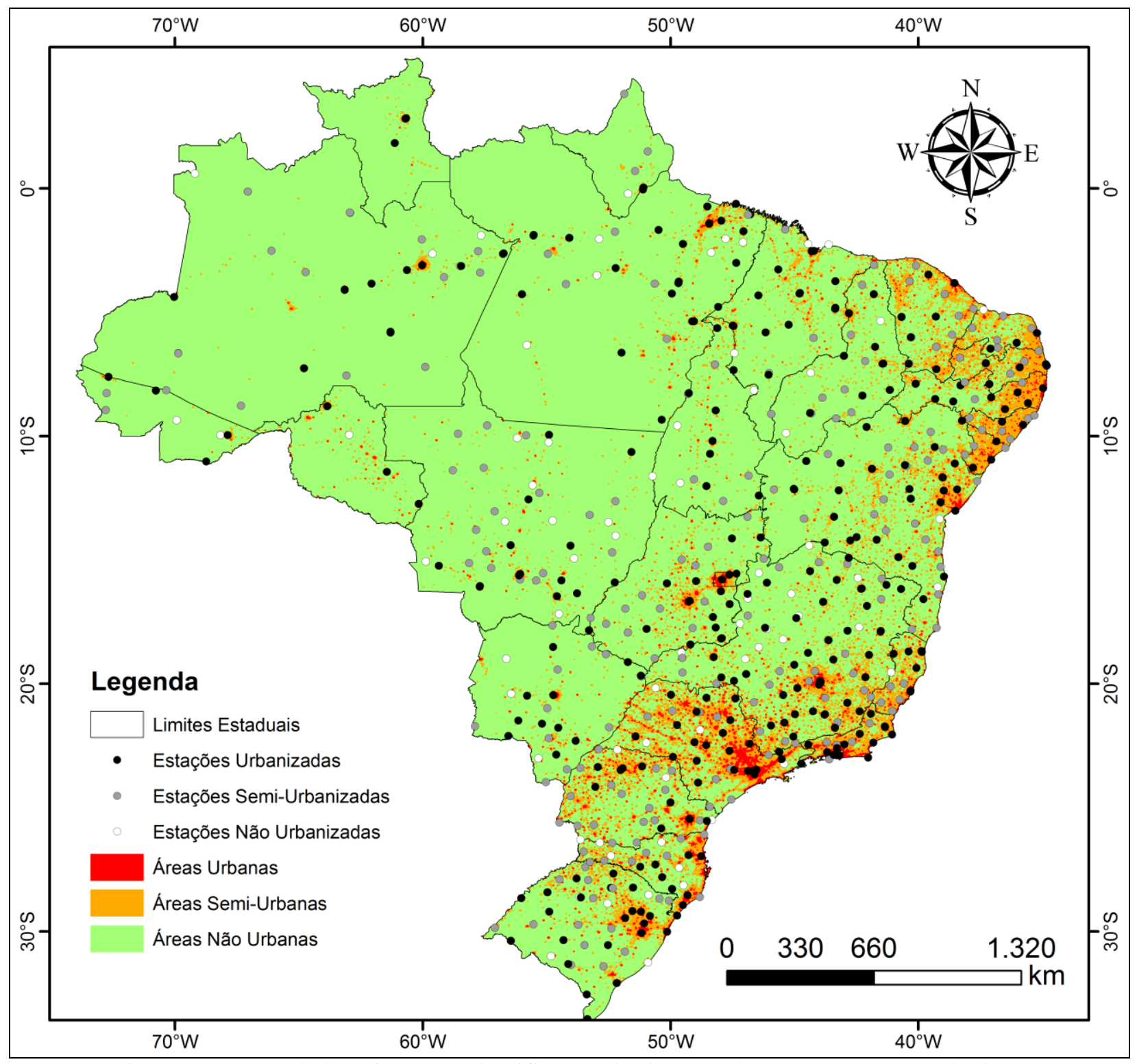

Figura 4 - Mapa da localização e classificação da situação das estações meteorológicas Elaboração: próprio autor. 
Quadro 1 - Quantidade e proporção de estações meteorológicas conforme a condição das estações meteorológicas.

\begin{tabular}{|c|c|c|c|c|c|c|}
\hline \multirow[b]{2}{*}{ Regiões/Condição das estacões } & \multicolumn{2}{|c|}{ Urbanizada } & \multicolumn{2}{|c|}{ Semiurbanizada } & \multicolumn{2}{|c|}{ Não Urbanizada } \\
\hline & Quant. & $\%$ & Quant. & $\%$ & Quant. & $\%$ \\
\hline Região Norte & 63 & 16,5 & 34 & 13,4 & 16 & 21,3 \\
\hline RO & 3 & 0,8 & 0 & 0,0 & 1 & 1,3 \\
\hline $\mathrm{AC}$ & 3 & 0,8 & 2 & 0,8 & 2 & 2,7 \\
\hline AM & 15 & 3,9 & 17 & 6,7 & 3 & 4,0 \\
\hline RR & 3 & 0,8 & 0 & 0,0 & 0 & 0,0 \\
\hline PA & 28 & 7,3 & 7 & 2,8 & 6 & 8,0 \\
\hline $\mathrm{AP}$ & 2 & 0,5 & 3 & 1,2 & 1 & 1,3 \\
\hline TO & 9 & 2,4 & 5 & 2,0 & 3 & 4,0 \\
\hline Região Nordeste & 118 & 31,0 & 87 & 34,3 & 12 & 16,0 \\
\hline MA & 18 & 4,7 & 7 & 2,8 & 5 & 6,7 \\
\hline PI & 14 & 3,7 & 11 & 4,3 & 3 & 4,0 \\
\hline $\mathrm{CE}$ & 11 & 2,9 & 14 & 5,5 & 0 & 0,0 \\
\hline $\mathrm{RN}$ & 5 & 1,3 & 8 & 3,1 & 1 & 1,3 \\
\hline $\mathrm{PB}$ & 7 & 1,8 & 7 & 2,8 & 0 & 0,0 \\
\hline $\mathrm{PE}$ & 15 & 3,9 & 5 & 2,0 & 0 & 0,0 \\
\hline $\mathrm{AL}$ & 4 & 1,0 & 7 & 2,8 & 0 & 0,0 \\
\hline SE & 5 & 1,3 & 3 & 1,2 & 0 & 0,0 \\
\hline $\mathrm{BA}$ & 39 & 10,2 & 25 & 9,8 & 3 & 4,0 \\
\hline Região Sudeste & 98 & 25,7 & 46 & 18,1 & 18 & 24,0 \\
\hline MG & 49 & 12,9 & 28 & 11,0 & 14 & 18,7 \\
\hline ES & 6 & 1,6 & 5 & 2,0 & 0 & 0,0 \\
\hline $\mathrm{RJ}$ & 15 & 3,9 & 5 & 2,0 & 0 & 0,0 \\
\hline SP & 28 & 7,3 & 8 & 3,1 & 4 & 5,3 \\
\hline Região Sul & 51 & 13,4 & 45 & 17,7 & 14 & 18,7 \\
\hline PR & 11 & 2,9 & 18 & 7,1 & 3 & 4,0 \\
\hline $\mathrm{SC}$ & 12 & 3,1 & 8 & 3,1 & 6 & 8,0 \\
\hline RS & 28 & 7,3 & 19 & 7,5 & 5 & 6,7 \\
\hline Região Centro-Oeste & 51 & 13,4 & 42 & 16,5 & 15 & 20,0 \\
\hline MS & 13 & 3,4 & 11 & 4,3 & 3 & 4,0 \\
\hline MT & 15 & 3,9 & 18 & 7,1 & 12 & 16,0 \\
\hline GO & 20 & 5,2 & 13 & 5,1 & 0 & 0,0 \\
\hline $\mathrm{DF}$ & 3 & 0,8 & 0 & 0,0 & 0 & 0,0 \\
\hline TOTAL & 381 & 100 & 254 & 100 & 75 & 100 \\
\hline
\end{tabular}

Elaboração: próprio autor, calculado em SIG.

No entanto, do montante de estações meteorológicas, vale frisar que 237 são do tipo convencionais, em que os dados são lidos e anotados diariamente por técnicos, posteriormente enviados à Central do INMET, 
e 473 são do tipo automáticas, que possuem unidade central de armazenamento automático de dados (datalogger) que faz o registro e posterior envio ao INMET.

Nesta divisão (convencional VS automática) há uma diferença considerável na condição de cobertura e uso do solo onde se situam. Dentre as 237 estações convencionais, 172 estão localizadas em áreas urbanas (73\%), 58 em semiurbanas (24\%) e 7 em áreas não urbanas (3\%) - Figura 5 (A), refletindo o quase predomínio dessas estações em áreas urbanas. Sendo estações mais antigas, possivelmente foram incorporadas pelo crescimento da área urbana.

Por sua vez, a quantidade de estações automáticas (473), 209 estão localizadas em áreas urbanas (44\%), 196 em semiurbana (44\%) e em áreas não urbanas 68 (14\%), indicando uma presença mais significativa dessas estações em áreas semiurbanas e, mesmo que parcamente, não urbanas - Figura 5 (B).

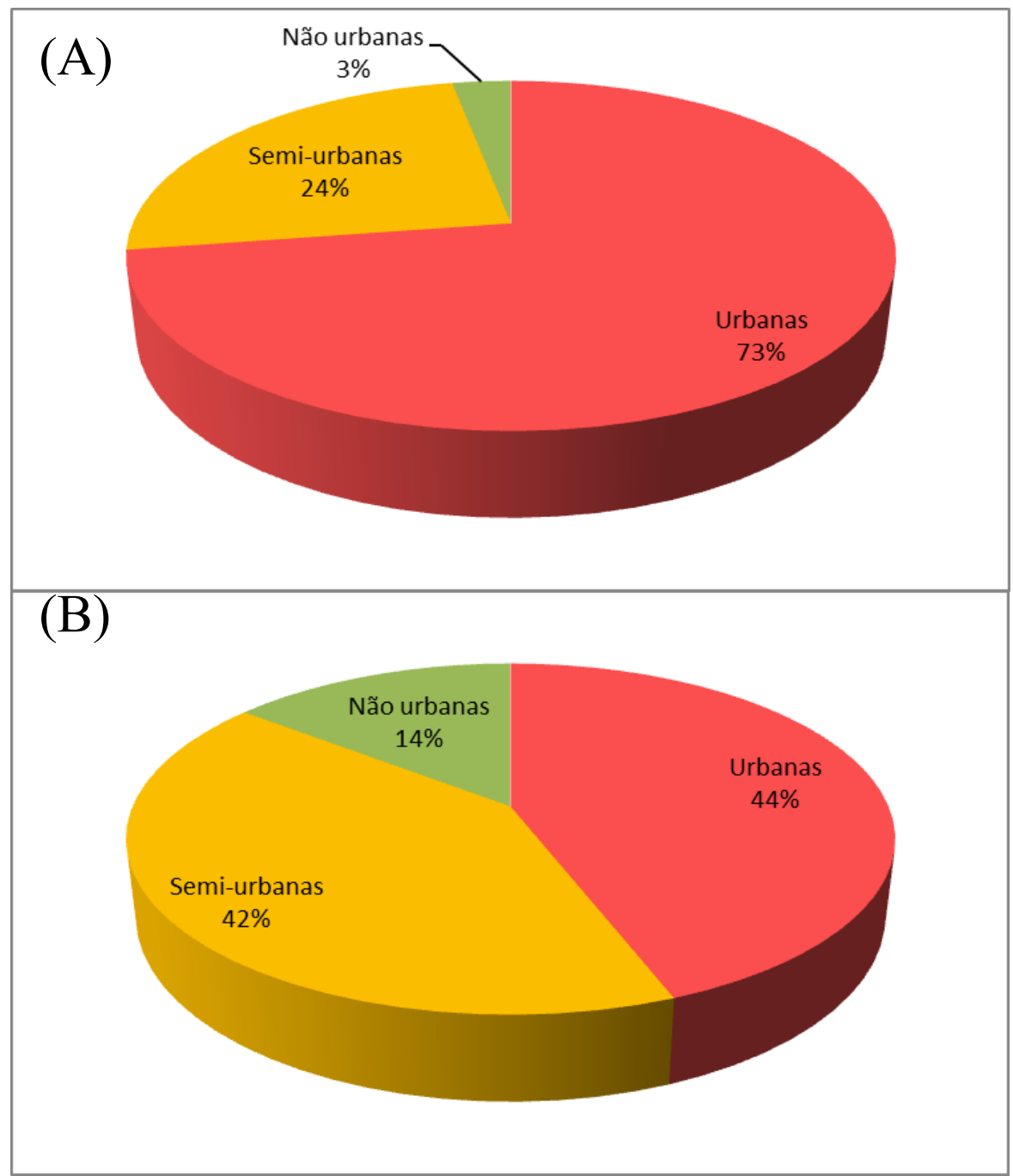

Figura 5 - Gráfico da situação das estações meteorológicas convencionais (A) e automáticas (B). Elaboração: próprio autor, calculado em SIG. 


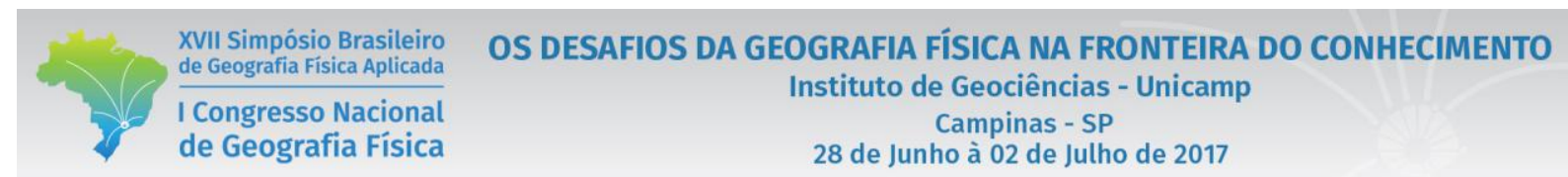

Na representação espacial das estações convencionais (Figura 6) e automáticas (Figura 7) é possível constatar que enquanto as estações convencionais (mais antigas e, por isso, fornecedoras de maiores séries temporais de dados) se concentram essencialmente nas Regiões Sudeste e Nordeste, a distribuição das estações automáticas (mais recentes e com menores séries temporais) é mais equilibrada em todas regiões brasileiras - o que mostra uma tentativa do INMET em proporcionar uma melhor distribuição do registro de seus dados.

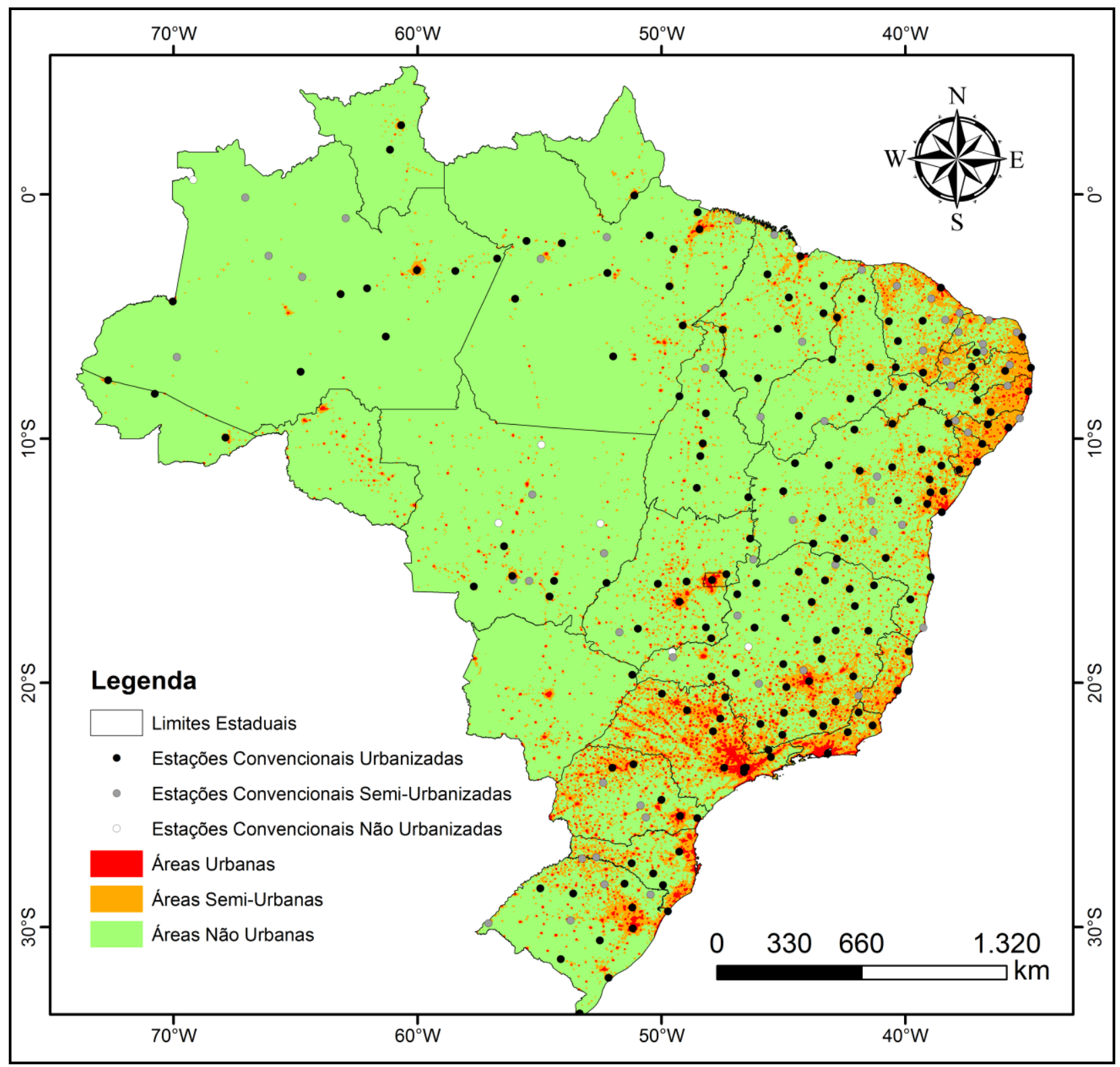

Figura 6 - Mapa com a localização e classificação da situação das estações meteorológicas convencionais Elaboração: próprio autor. 

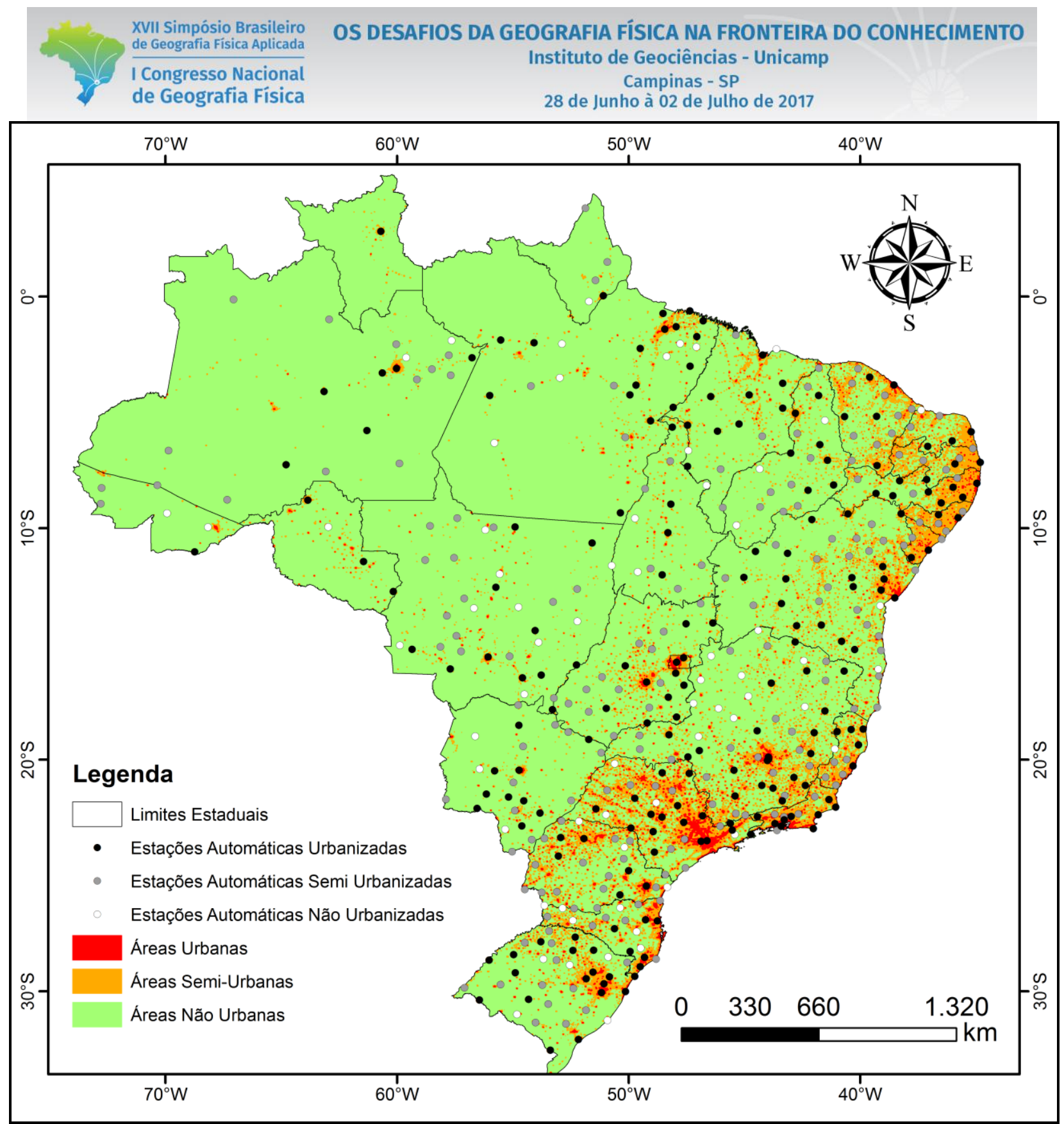

Figura 7 - Mapa com a localização e classificação da situação das estações meteorológicas automáticas

Elaboração: próprio autor.

As estações convencionais situadas em áreas urbanas se concentram principalmente no Nordeste $(34,9 \%)$ e Sudeste (25,6\%), enquanto que aquelas situadas em áreas semiurbanas ocorrem principalmente nas regiões Nordeste $(48,3 \%)$ e Sul $(15,5 \%)$ e, em áreas não urbanas, nas regiões Centro-Oeste $(42,9 \%)$ e Sudeste $(28,6 \%)$ - Quadro 2.

Dentre as estações automáticas posicionadas em áreas urbanas, a maior proporção se dá nas regiões Nordeste $(27,8 \%)$ e Sudeste $(25,8 \%)$, havendo mesma condição com relação às estações situadas em áreas semiurbanizadas, com o Nordeste apresentando concentração de 30,1\% e o Sudeste de 19,9\%. No caso das 
estações automáticas localizadas em áreas não urbanizadas, diferentemente do caso das estações convencionais, a maior concentração se dá nas regiões Sudeste $(23,5 \%)$ e Norte $(22,1 \%)$.

Quadro 2-Quantidade e proporção de estações meteorológicas conforme a condição das estações convencionais.

\begin{tabular}{|c|c|c|c|c|c|c|}
\hline \multirow[b]{3}{*}{ Regiões/Condição das estações } & \multicolumn{6}{|c|}{ Convencionais } \\
\hline & \multicolumn{2}{|c|}{ Urbanizada } & \multicolumn{2}{|c|}{ Semiurbanizadas } & \multicolumn{2}{|c|}{ Não Urbanizada } \\
\hline & Quant. & $\%$ & Quant. & $\%$ & Quant. & $\%$ \\
\hline Região Norte & 31 & 18,0 & 9 & 15,5 & 1 & 14,3 \\
\hline RO & 0 & 0,0 & 0 & 0,0 & 0 & 0,0 \\
\hline $\mathrm{AC}$ & 2 & 1,2 & 0 & 0,0 & 0 & 0,0 \\
\hline $\mathrm{AM}$ & 9 & 5,2 & 5 & 8,6 & 1 & 14,3 \\
\hline RR & 2 & 1,2 & 0 & 0,0 & 0 & 0,0 \\
\hline PA & 12 & 7,0 & 3 & 5,2 & 0 & 0,0 \\
\hline $\mathrm{AP}$ & 1 & 0,6 & 0 & 0,0 & 0 & 0,0 \\
\hline TO & 5 & 2,9 & 1 & 1,7 & 0 & 0,0 \\
\hline Região Nordeste & 60 & 34,9 & 28 & 48,3 & 1 & 14,3 \\
\hline MA & 9 & 5,2 & 3 & 5,2 & 1 & 14,3 \\
\hline PI & 7 & 4,1 & 2 & 3,4 & 0 & 0,0 \\
\hline $\mathrm{CE}$ & 6 & 3,5 & 5 & 8,6 & 0 & 0,0 \\
\hline RN & 2 & 1,2 & 5 & 8,6 & 0 & 0,0 \\
\hline PB & 4 & 2,3 & 2 & 3,4 & 0 & 0,0 \\
\hline $\mathrm{PE}$ & 6 & 3,5 & 2 & 3,4 & 0 & 0,0 \\
\hline $\mathrm{AL}$ & 2 & 1,2 & 3 & 5,2 & 0 & 0,0 \\
\hline SE & 3 & 1,7 & 0 & 0,0 & 0 & 0,0 \\
\hline BA & 21 & 12,2 & 6 & 10,3 & 0 & 0,0 \\
\hline Região Sudeste & 44 & 25,6 & 7 & 12,1 & 2 & 28,6 \\
\hline MG & 27 & 15,7 & 7 & 12,1 & 2 & 28,6 \\
\hline ES & 2 & 1,2 & 0 & 0,0 & 0 & 0,0 \\
\hline RJ & 4 & 2,3 & 0 & 0,0 & 0 & 0,0 \\
\hline SP & 11 & 6,4 & 0 & 0,0 & 0 & 0,0 \\
\hline Região Sul & 20 & 11,6 & 9 & 15,5 & $\mathbf{0}$ & $\mathbf{0 , 0}$ \\
\hline PR & 5 & 2,9 & 3 & 5,2 & 0 & 0,0 \\
\hline $\mathrm{SC}$ & 5 & 2,9 & 1 & 1,7 & 0 & 0,0 \\
\hline RS & 10 & 5,8 & 5 & 8,6 & 0 & 0,0 \\
\hline Região Centro-Oeste & 17 & 9,9 & 5 & 8,6 & 3 & 42,9 \\
\hline MS & 2 & 1,2 & 0 & 0,0 & 0 & 0,0 \\
\hline MT & 5 & 2,9 & 4 & 6,9 & 3 & 42,9 \\
\hline GO & 9 & 5,2 & 1 & 1,7 & 0 & 0,0 \\
\hline DF & 1 & 0,6 & 0 & 0,0 & 0 & 0,0 \\
\hline TOTAL & 172 & 100,0 & 58 & 100,0 & 7 & 100,0 \\
\hline
\end{tabular}

Elaboração: próprio autor, calculado em SIG. 
Quadro 3-Quantidade e proporção de estações meteorológicas conforme a condição das estações automáticas.

\begin{tabular}{|c|c|c|c|c|c|c|}
\hline \multirow{3}{*}{ Regiões/Condição das estações } & \multicolumn{6}{|c|}{ Automáticas } \\
\hline & \multicolumn{2}{|c|}{ Urbanizada } & \multicolumn{2}{|c|}{ Semiurbanizadas } & \multicolumn{2}{|c|}{ Não Urbanizada } \\
\hline & Quant. & $\%$ & Quant. & $\%$ & Quant. & $\%$ \\
\hline Região Norte & 32 & 15,3 & 25 & 12,8 & 15 & 22,1 \\
\hline RO & 3 & 1,4 & & 0,0 & 1 & 1,5 \\
\hline $\mathrm{AC}$ & 1 & 0,5 & 2 & 1,0 & 2 & 2,9 \\
\hline $\mathrm{AM}$ & 6 & 2,9 & 12 & 6,1 & 2 & 2,9 \\
\hline $\mathrm{RR}$ & 1 & 0,5 & 0 & 0,0 & 0 & 0,0 \\
\hline PA & 16 & 7,7 & 4 & 2,0 & 6 & 8,8 \\
\hline $\mathrm{AP}$ & 1 & 0,5 & 3 & 1,5 & 1 & 1,5 \\
\hline TO & 4 & 1,9 & 4 & 2,0 & 3 & 4,4 \\
\hline Região Nordeste & 58 & 27,8 & 59 & 30,1 & 11 & 16,2 \\
\hline MA & 9 & 4,3 & 4 & 2,0 & 4 & 5,9 \\
\hline PI & 7 & 3,3 & 9 & 4,6 & 3 & 4,4 \\
\hline $\mathrm{CE}$ & 5 & 2,4 & 9 & 4,6 & 0 & 0,0 \\
\hline $\mathrm{RN}$ & 3 & 1,4 & 3 & 1,5 & 1 & 1,5 \\
\hline PB & 3 & 1,4 & 5 & 2,6 & 0 & 0,0 \\
\hline $\mathrm{PE}$ & 9 & 4,3 & 3 & 1,5 & 0 & 0,0 \\
\hline $\mathrm{AL}$ & 2 & 1,0 & 4 & 2,0 & 0 & 0,0 \\
\hline SE & 2 & 1,0 & 3 & 1,5 & 0 & 0,0 \\
\hline BA & 18 & 8,6 & 19 & 9,7 & 3 & 4,4 \\
\hline Região Sudeste & 54 & 25,8 & 39 & 19,9 & 16 & 23,5 \\
\hline MG & 22 & 10,5 & 21 & 10,7 & 12 & 17,6 \\
\hline ES & 4 & 1,9 & 5 & 2,6 & 0 & 0,0 \\
\hline RJ & 11 & 5,3 & 5 & 2,6 & 0 & 0,0 \\
\hline SP & 17 & 8,1 & 8 & 4,1 & 4 & 5,9 \\
\hline Região Sul & 31 & $\mathbf{1 4 , 8}$ & 36 & 18,4 & 14 & 20,6 \\
\hline PR & 6 & 2,9 & 15 & 7,7 & 3 & 4,4 \\
\hline $\mathrm{SC}$ & 7 & 3,3 & 7 & 3,6 & 6 & 8,8 \\
\hline RS & 18 & 8,6 & 14 & 7,1 & 5 & 7,4 \\
\hline Região Centro-Oeste & 34 & 16,3 & 37 & 18,9 & 12 & 17,6 \\
\hline MS & 11 & 5,3 & 11 & 5,6 & 3 & 4,4 \\
\hline MT & 10 & 4,8 & 14 & 7,1 & 9 & 13,2 \\
\hline GO & 11 & 5,3 & 12 & 6,1 & 0 & 0,0 \\
\hline DF & 2 & 1,0 & & 0,0 & & 0,0 \\
\hline TOTAL & 209 & 100,0 & 196 & 100,0 & 68 & 100,0 \\
\hline
\end{tabular}

Elaboração: próprio autor, calculado em SIG. 


\section{Conclusão}

Pelos dados representados foi possível constatar que maior parte das estações do INMET está localizada em áreas urbanas ou semiurbanas, indicando que os dados meteorológicos registados atualmente sofram a influência de zonas urbanizadas, ocorrendo num padrão distinto pelas regiões brasileiras e, principalmente, dentre as estações do tipo convencional e automática.

Esse fato permite inferir as tendências, variações ou mesmo mudanças na série temporal dos dados, particularmente referente à temperatura e umidade relativa do ar. Isso porque a supressão da vegetação natural, associada ao calor gerado pelos edifícios e atividades antrópicas, às alterações na composição atmosférica e às mudanças na velocidade e no fluxo de ventos, promove a modificação do balanço de energia na atmosfera urbana - resultando em mudanças climáticas na escala local das cidades.

Contudo os resultados ora apresentados se referem apenas à realidade espacial de 2012 (ano das imagens empregadas no presente estudo), e, embora a história da urbanização brasileira permita tais inferências, não há como afirmar se as estações que hoje estão em áreas urbanizadas passaram ou não por mudanças na cobertura do solo que reflitam em tais alterações nos dados meteorológicos. Assim, como sugestão de continuidade dessa pesquisa, sugere-se a análise de séries temporais de dados das estações meteorológicas acompanhada do mapeamento da evolução de cobertura do solo no entorno das mesmas, para que seja passível constatar se as mudanças de cobertura de solo realmente se relacionam às tendências, variações e mesmo mudanças dos elementos climáticos.

\section{Bibliografia}

DUBREUIL, V. Clima e Teledetecção: uma abordagem geográfica. Revista Brasileira de Climatologia, v. 1, n. 1, p. 76-99, 2005.

ROZANTE, J. R.; MOREIRA, D. S.; GONÇALVES, L. G. G. DE.; VILA, D. D. Combining TRMM and Surface Observation of Precipitation: technique and validation over South America. Weather and forecasting, v. 25, 885-894, 2010.

SU, F.; HONG, Y.; LETTENMAIER, D. P. Evaluation of TRMM multisatellite precipitation analysis (TMPA) and its utility in hydrologic prediction in the La Plata basin. Journal of Hydrometeorology, v. 9, p. 622-641, 2008.

YANG, J. et al. The role of satellite remote sensing in climate change studies. Nature Climate Change, v. 3, p. 875-886, 2013. 